\title{
La forma perfecta: Sarlo lee a Saer*
}

The Perfect Form: Sarlo Reads Saer

Miguel Dalmaroni ${ }^{\text {a }}$

Universidad Nacional de La Plata, Argentina

DOI: https://doi.org/10.11144/Javeriana.cl24.fpsl

dalmaroni@gmail.com

Recibido: 30 Mayo 2017

Aceptado: 11 Septiembre 2017

Publicado: 28 Diciembre 2020

\section{Resumen:}

La característica principal de la lectura sarliana de Saer es una modalidad particular de formalismo. Este se trata de un impulso de lectura que reside en la articulación del enfoque en la técnica artística (poética, narrativa), considerada semánticamente funcional, recuperable y decidible; y en la relación entre esa poética de la forma y un programa intertextual en cuyo centro está Borges, con el lugar que le corresponde a Saer en la historia literaria argentina, y como consecuencia de la constancia vertebradora de esa apuesta formal e intertextual, un juicio acerca del valor máximo de la obra de Saer, que para Sarlo es "perfecta”. Al mismo tiempo, se ensayan aquí aproximaciones a un eventual punto ciego de esa lectura.

Palabras clave: Saer, Sarlo, Borges, forma, técnica, formalismo.

\begin{abstract}
:
The main characteristic of Sarlo's reading of Saer is a peculiar type of formalism. Her reading impulse lies in this articulation: the focus on the artistic technique (poetic, narrative), considered semantically functional, recoverable, and subject to a decisionmaking process; the relationship between that poetic of the form and an intertextual program whose center is Borges, with Saer's corresponding place in the history of Argentinian literary history, and, as a consequence of the unifying force of that formal and intertextual approach, a judgement about the highest value of Saer's work arises, which Sarlo describes as "perfect." At the same time, our paper develops approximations to a potential blind spot in that reading.
\end{abstract}

Keywords: Saer, Sarlo, Borges, form, technique, formalism.

A partir de Cicatrices todas las novelas de Saer son formalmente perfectas.

Beatriz Sarlo, "Juan José Saer: cicatrices de una larga ausencia”, Duchini ${ }^{1}$

Beatriz Sarlo es una lectora integral, moderna y formalista. La figura del lector integral es un invento de George Steiner, quien, en las primeras páginas de su libro Después de Babel, proponía, mediante cuatro breves ejercicios de interpretación, desentrañar la integridad semántica de un texto -leer para comprender, es decir, para abarcar y entender-, y llegar a saber así cabalmente y de un modo fiable qué significados reúne una obra literaria (y, por tanto, cuáles no). Nomás en la segunda página de su libro, Steiner advierte las dificultades severas que nos plantea el escurridizo sentido de una sola palabra en un parlamento de Shakespeare, y, a la vez, que no sabremos nunca qué entendían los contemporáneos del teatro isabelino cuando la escuchaban pronunciada en el escenario. Steiner, uno de esos filólogos europeos que todavía a fines del siglo XX reunía saberes políglotas que ya nadie suma, fracasa en su ideal imposible de la lectura integral, pero el camino a ese fracaso es lo que le permite exhibir cuán docto hay que ser, parece, para entender. Steiner no lo admitiría en estos términos, pero el lector que se sueña capaz de recuperar todas las determinaciones de un texto y restituir su sentido descubre pronto que no es menos ignorante ni menos caprichoso, al fin, que the common reader. La distancia que nos separa de Shakespeare no es más severa que la que mantenemos con el más próximo de

Notas de autor

\footnotetext{
${ }^{\text {a }}$ Autor de correspondencia. Correo electrónico: dalmaroni @gmail.com
} 
nuestros contemporáneos (porque, como advirtieron Blanchot y Badiou, lo que importa de la distancia es su irreductibilidad, eso que la hace — aun si es ínfima — infinita).

Beatriz Sarlo es una lectora integralista, moderna y formalista: busca leer un sentido y confía en que eso es posible porque el sentido está en la forma (y en la historia de las formas que precede a la forma), y la crítica consiste en entender la forma, y, por tanto, la trama intertextual en la que se apoya. Aunque conozcan todas las epistemologías de la incertidumbre, desde Freud y Lacan hasta la mistica de la física de partículas, los lectores modernos son tales porque siguen inclinándose por la búsqueda del sentido, del sentido determinado en y por las invenciones formales. El último Barthes enseñaba que "la pregunta propia de la lectura" es "no qué texto leo, sino quétexto soy" si leo (El discurso amoroso 269). La crítica modernista prefiere más bien no poner en el foco principal de sus indagaciones ese acto contingente, incalculable y agujereado de lectura actuado por cualquiera, actuado por un texto en no importa quién, la lectura de quienes no solo ignoran, sino que además no creen saber lo que ignoran - Steiner nos hace suponer, de manera tramposa o inadvertidamente contradictoria, que personas como él podrían saber todo lo que ignoramos, todo eso que haría falta para entender qué demonios quiso decir Póstumo en el parlamento de Cimbelino en el que usa la palabra counterfeit de un modo que la dejó, en verdad, enrarecida para siempre (Después 24-25) - . La crítica literaria y cultural moderna no resigna, empero, la expectativa de comprender: se mueve sobre el suelo de una racionalidad para la cual sin duda quien conozca las películas de Alfred Hitchcock entenderá mejor las de Brian De Palma; o quien haya leído a Kafka entenderá mejor a Borges que alguien que no. Como Shakespeare y Austen, según Steiner, Sarlo también cree que la de Saer es una obra para "entendidos" (Zona Saer 84). Conocemos, por lo menos, algunas de las innegables ventajas y los enormes provechos intelectuales, culturales y estéticos de leer de ese modo. Pero ese modo de leer no parece el más interesado, en cambio, en todo lo que sucede cuando, mucho más a menudo que en la mesa de trabajo del crítico especializado, los lectores, integrales o comunes y corrientes, hacen lo que pueden, lo que se supone que no deberían y, siempre, lo que les sale con el texto que llega a sus manos. Por supuesto, son muchos más los lectores de Saer que han leído poco o nada a Joyce, menos a Michel Butor o a Robbe Grillet o a los viajeros ingleses del siglo XIX (pero que no por eso quedan menos intensamente afectados por leer a Saer que un erudito, estudioso, docto o entendido). Los lectores de Saer que no encontrarían en sus relatos una resonancia hernandiana o un eco de Antonio Di Benedetto ya superan abrumadoramente en número a los que sí. ¿Por qué, para un trabajo que merezca la calificación de crítico, sería más importante el Saer del lector que pesca “Tema del traidor y del héroe" al comienzo de Glosa que el que no lo hace, mientras, en cambio, piensa en Rayuela cuando ve en las dos novelas un grupo de jóvenes más o menos bohemios, tapados de libros y citas, todos más o menos escritores y artistas, o intelectuales, caminantes infatigables y aleatorios de la ciudad, sofistas etílicos de pacotilla, entre sartreanos y conceptualistas, intermitentemente reunidos en torno de un maestro-gurú enemigo de la novela (Morelli, Washington, ¿no?)? ¿Por qué esa operación de lectura —que tomo de un par de escenas de lectura de hace unos años, una escolar y otra social - tendría menos importancia crítica e histórica que otras, por caso, que las del Saer lector de sí mismo, o que las de los críticos cuyas preferencias estéticas, cuyo gusto están más cerca del de Saer? Pero conviene llevar más lejos esta conjetura: ¿qué nos obliga a suponer que el conocimiento de los saberes literarios y artísticos con que Saer compuso su modo de narrar conduce a una lectura preferible de los escritos que llevan su firma, o incluso a una lectura más propia de un estudio especializado ${ }^{2}$ ¿Por qué leer La grande teniendo presente lo que sabemos si leímos antes La vuelta completa estaría más cerca de una lectura preferible? Sarlo es una lectora moderna porque pertenece a una era en la que la cultura más autorizada entiende que la literatura - que a su manera reúne y condensa todo lo decible por las ideologías, el sentido común o los imaginarios - se lee entonces desde sí misma. Por supuesto que, si tomamos, por ejemplo desde la Argentina, a Borges para describir la literatura como un extenso, sesgado y complejo documento de la cultura de su tiempo en su conjunto, leer a Borges es leer esa cultura y, al mismo tiempo, el revés crítico de tu trama, el develamiento de su condición ideológica. La cuestión, sin embargo, residiría en saber si leer a Borges es eso o, en cambio, una especie de desencuentro con cierto afuera, cierto excedente o cierta ajenidad que la cultura, 
no bien lo ve insinuarse, se ocupa de triturar, aplanar y suprimir en la familiarización de lo mismo (pienso en cómo Lacan propone esto en Mi enseñanza [91]).

Así, todo el argumento de las notas que siguen podría sintetizarse de este modo: en un mismo movimiento, Sarlo lee una determinada idea de la forma que es una cierta idea de la historicidad de la literatura y que se cursa en intertextualidades (tramadas estas siempre con alguna sociabilidad historizable, un determinado espacio sociocultural o un campo literario particular). El movimiento puede describirse en un círculo: la forma es su historia, la cual es una historia de intertextualidades sociables que son, así mismo, formas históricas, y así sucesivamente. Ese círculo es la condición de la lectura y es siempre en su interior y según su ritmo propio que, entonces, se lee allí, a la vez, lo otro de la literatura, que en Sarlo es sobre todo la ciudad, las ideas y las artes, y la política - los grandes nudos modernistas para hablar de la cultura-.

Como buena moderna, además de integral y formalista, Sarlo ha sido por décadas, característicamente, una voluntariosa y enfática promotora de lo que llamó con insistencia el valor literario, especialmente en lo relativo a la historia de la literatura argentina y al debate sobre el canon: a ella siempre le ha interesado plantear e irradiar sus juicios sobre quiénes son los mejores. Su repetida calificación de "perfecta" para la obra de Saer es un aserto superlativo cuyas pretensiones de verdad no se pueden eludir. Quizás este sea además un modo de manifestar una convicción y acaso un estado efectuado por el encuentro de una lectora con una obra, pero es, al mismo tiempo, una intervención que, junto con otros modos de la polémica, pretende orientar el debate sobre el canon.

Empecé a leer a Beatriz Sarlo muy poco antes que a Saer. Desde inicios de los años ochenta fui leyéndolos a medida que publicaban, y como tantos de mis pares les dediqué años de estudio, escritos, relecturas, clases, seminarios y ensayos. Leí por primera vez cada uno de los textos de Sarlo sobre Saer más o menos cuando se publicaron, con los obvios intervalos del caso y mucho antes de releerlos todos juntos para escribir este ensayo. En esos intervalos, por supuesto, me atravesaron las conversaciones y polémicas del mundillo literario y universitario sobre esas dos firmas y sus cruces, encuentros y desencuentros con muchas otras; pero también presté toda la atención que pude a la circulación y las lecturas de Saer en otros ámbitos, especialmente en las escuelas secundarias argentinas; con éxito módico y dispar, pero con algún resultado útil, creo, traté siempre de encontrar y retener relatos de lectores ajenos a los círculos saerianos de culto y a las creencias y los hábitos de la comunidad crítica especializada. No conversé nunca con Saer personalmente, pero, una vez, cuando una lectora de Borges, que me decía que para ella la literatura era Borges, me preguntó quién lo era para mí, dije sin pensar demasiado: "Sin contar a unos pocos poetas, Saer y Puig". Con Beatriz Sarlo sí hablé muchas veces; fue una de las principales maestras con quien mi generación se formó y aprendió a leer, a discutir y a escribir. Aunque otros hayamos dado a conocer una cantidad voluntariosa e innecesaria de páginas sobre la literatura de Saer, para mí son María Teresa Gramuglio, Alberto Giordano y Sarlo las tres firmas que con más acierto crítico han publicado los principales descubrimientos e ideas que conozco sobre la obra de Saer. Necesitaron pocas páginas para hacerlo.

Hubo parte de una generación de argentinos que alcanzó a sentirse (o a desearse), parece, como un personaje de algún relato de Cortázar, digamos de Rayuela. Pertenezco a quienes, en cambio, entre avergonzados y autoirónicos, nos descubrimos imaginándonos en alguna de "esas largas conversaciones deshilachadas" (Sarlo, Escenas 145) con Tomatis y los mellizos Garay, digamos, en Glosa... o con Saer en el departamento de la calle Talcahuano, donde funcionaba Punto de Vista, o en la terraza de la casa de Caballito, donde vivían Juan Pablo Renzi y Gramuglio. Todos (aquellos lectores de Cortázar y estos de Saer) nacimos por lo menos veinte años después de esos personajes y de esas personas.

Cuando comencé a escribir estas notas suponía que le estaba dando forma a un paper, un escrito de investigación. No mucho después empecé a descubrir que, todo el tiempo, el tema me traía a su terreno también como informante, como fuente primaria, aunque no lo fuese privilegiada o de primer orden, y que estaba escribiendo no solo como investigador, sino además como un testigo en los suburbios de una historia de la que alcancé a ver algo mientras se produjo, envuelto en los arrabales del asunto. Lo que sigue es, por eso, 
un testimonio de lector y no solo un estudio, el ensayo en primera persona de un personaje muy secundario y esporádico en esa sobria y rara historia de amor literario que protagonizaron, eminentes, una lectora tenaz y un artista único. Por supuesto, me refiero a lo que, de todo eso, reviste interés crítico e histórico: lo que sé sobre el tema porque lo vi, lo escuché mientras sucedía, lo fui acopiando en una memoria de lo que transcurría (cuando yo tenía 20 años, Saer llegaba apenas a los 41 y ya había publicado La mayor). El lector estudioso que extrañe aquí mayores detalles de erudición copiosa, o más argumentos siempre acompañados de suficientes citas textuales y de corroboraciones menos escuetas, o los pormenores rigurosos de las notas de investigación, puede fatigarse, si lo desea, con mis otros escritos sobre Saer, en especial con "El largo camino del 'silencio' al 'consenso'. La recepción de Saer en la Argentina (1964-1987)".

La tarde de 2016 en que Beatriz Sarlo me regaló un ejemplar de Zona Saer (en ese momento su último libro, dedicado por entero al escritor santafecino) hablamos un poco de Borges, de mi idea ciclotímica e imprecisa de escribir un libro imposible enteramente dedicado a "Tema del traidor y del héroe”. “¡Naturalmente! me dijo-, lo que todos los críticos argentinos sabemos que haremos algún día, un libro sobre Borges”. No apostaría a que Sarlo utilizaría alguna vez la misma frase para referirse a Saer, pero, por supuesto, es imposible pensar su labor crítica, su trayectoria - los rasgos característicos, la importancia, los alcances de la obra de Sarlo-, sin considerar como uno de sus ejes principales esa prolongada intervención en torno de Juan José Saer que comenzó en la revista Los Libros en 1976, pero especialmente en Punto de Vista, en 1980 ("Saer, Tizón, Conti", "Narrar la percepción”, en Sarlo, Escritos 281-285). De hecho, los escritos críticos extensos que Sarlo dedicó en libros y por entero a la obra de una firma son esos dos: Borges: un escritor en las orillas (1995) y Zona Saer (2016). ${ }^{3}$ Se sabe: para Sarlo, Saer es "el mejor" escritor argentino después de Borges y hasta el presente de estas notas (en 2016 escribió que "fue, simplemente, un escritor descomunal" [Sarlo, Zona Saer 9]). ${ }^{4} \mathrm{Al}$ mismo tiempo, para la autora de Una modernidad periférica parece clave considerar la poética y las elecciones artísticas de casi cualquier escritor argentino importante de la segunda mitad del siglo XX como el resultado de una confrontación obligada con Borges, que razona con figuras como ajuste o arreglo de cuentas, duelo o batalla, y que en el caso de Saer llega al extremo: el santafecino no solo "temía su admiración" por Borges, de quien necesitaba "defenderse"; además, debía "matar a Borges" (Sarlo, Zona Saer 23, 25, 29). ¿La vida literaria vista como una novela de crímenes, como un ajuste de cuentas con el capi de la ficción? Alguna vez convendría interrogar esas autoficciones asesinas y edípicas de las letras (junto con otros autobombos retóricos, por ejemplo, el del escritor parricida) como síntomas, anhelos de época, sueños de un mundillo que sus habitantes querríamos, parece, menos módico o menos fútil. Estos son síntomas o contaminaciones críticas de la imaginación sanguinaria, compadrita y aventurera del propio Borges o, tal vez, son el mero anhelo literario de aventuras y vidas memorables (siempre se puede calmar un poco el tedio de la vida literaria o, peor, de su historia — tanto como la desproporción entre el poder de la literatura para cautivar a millones y la impotencia de los dimes y diretes de la sociabilidad literaria para hacer algo ni remotamente comparable - imaginando que los escritores pugnan entre sí como duelistas, matones o vengadores de un relato argentino). Como sea, lo que cuenta es ese énfasis que Sarlo casi nunca modera, y que en el libro de 2016 lleva al extremo del asesinato figurado, ya que, si para sacarse de encima a Borges hay que matarlo, nadie aparte de Saer sería lo suficientemente enorme para convertirse en un magnicida. Creo que Sarlo exagera el peso de la relación de Saer con Borges (así como exagera cuando dice que escribir un libro sobre Borges es el destino de todo crítico argentino). Esto se debe no solo a preconceptos propios de la vanguardia literaria, crítica y universitaria del siglo XX (lectora de una biblioteca de sociología belicista de la vida literaria, encabezada por Bourdieu), ${ }^{5}$ sino, además, a un motivo muy importante: si Saer, como quiere Sarlo, superó o resolvió de modo tan definitivo y completo una relación con Borges que lo haya liberado de toda subordinación, y si hacerlo fue saldar una cuenta pendiente mortal, sin dudas se puede decir entonces que Saer logró ser, nomás, como quiere Sarlo, "el mejor", y serlo a secas: no meramente el mejor de los narradores argentinos. Hace poco, el escritor Edgardo Scott, informante atento y de primera mano, me decía que un amigo común, novelista argentino de elogiada inteligencia crítica e ingenio retórico, influyente en el ámbito universitario y con muy 
alto reconocimiento internacional y respaldo editorial, suele asegurar en dialecto rioplatense que "Borges fue realmente el que la pegó de veras", debido a que el mundo da por sentado que es excelente, superlativo, pero a la vez único, una antonomasia imaginada sin contextos: en Europa, Borges no es un escritor latinoamericano, ni es un escritor argentino en ninguna parte (ni siquiera en Argentina alcanza a serlo, o no termina de serlo). Borges es Borges, nomás. Me interesan esas conversaciones entre escritores y entre escritores críticos, por supuesto, no porque sean verdaderas o falsas, sino porque nos proporcionan un territorio de juicios y fronteras de época contra el que dirimimos y adoptamos valoraciones. No es casual, por supuesto, que una de las insistencias de Sarlo sea esa: Saer es no solo un gran escritor argentino, ni siquiera apenas uno de los mejores escritores contemporáneos en castellano, sino uno de los mejores sin más. Sin demarcaciones geográficas, sin el pasaporte de una región cultural; "sin atributos", como quería el propio Saer. ${ }^{6}$ Aun si creyésemos que la de Saer es una literatura "perfecta", convendría interrogar, sin embargo, la idea de que debido a eso ocupó, en efecto, el espacio de Borges, o un lugar propio y singular, pero comparable al de Borges. No lo parece, si diésemos por hecho que Borges se volvió muy traducible e internacional debido no solo a las estratagemas de mercado o del "campo" editorial y crítico, sino principalmente a su castellano, a sus temas, a las invenciones de su imaginación y a la fluidez legible de la arquitectura de sus tramas; algo que a doce años de su muerte no ha sucedido con Saer: si es en tal sentido (aunque no lo sea solo en ese) que Borges "la pegó", entonces, hay que reconocer que Saer no lo hizo. Y no la pegó casi por motivos contrarios, entre los que se cuentan sin duda la sintaxis imposible de su prosa, su característica demora detallista, interminable, en "narrar la percepción", y su muy escasa y, a lo sumo, fragmentada adopción de una narratividad de sucesos concatenados y de la relación de destinos (en las conversaciones de la vida literaria desde los años ochenta en la Argentina, y por lo menos hasta Lo imborrable, para muchos el problema de las novelas de Saer era que en ellas "no pasa nada" o que estas "no cuentan una historia”). ${ }^{8}$ Para sopesar esta diferencia importante de lugares, sitiales o niveles de consagración y canonización alcanzados por uno y otro (es decir, para no sobreestimar la figura del ajuste de cuentas o el parricidio, ni menos su supuesto resultado), hay que hacer el ejercicio de imaginar escribiendo sobre Saer, como lo hicieron sobre Borges, a gente como Harold Bloom o George Steiner, o por lo menos a un Jacques Rancière (Bloom El canon occidental; Steiner, "Los tigres en el espejo"; Rancière, Politique de la littérature).

Esa referencia a Borges como algo, digamos, de vida o muerte y además insoslayable, casi machacona, en fin, el énfasis en semejante clase de intertextualidad, es uno de los principales componentes historicistas del formalismo de Sarlo: lectora de Theodor Adorno, pero también de Raymond Williams, para Sarlo las formas tienen siempre una historia, y la historia cultural es la historia de las formas, es decir, del encuentro siempre situable entre tradiciones e innovación, entre las convenciones disponibles y las invenciones artísticas, intelectuales o políticas del presente. La ocasión y Las nubes, por ejemplo, son principalmente para Sarlo lo que Saer es capaz de hacer con géneros literarios históricos codificados, "formas plenas de la novela" — novela sentimental, de aventuras, de viaje, filosófica, de caracteres- que "han sido debilitadas por la desconfianza" (Sarlo, Escritos 296). Formas de cuya historia, en fin, no es posible prescindir si queremos entender la poética del santafecino. ${ }^{9}$ La lógica de ese historicismo formalista o ese formalismo historicista está también en la intertextualidad que Sarlo razona para describir la relación de Saer con los escritores precedentes y coetáneos. En formulaciones más bien breves, pero importantes para una historia de la literatura argentina del siglo XX, sus ensayos incluyen señalamientos sobre las relaciones de Saer con el Martín Fierro, con Juan L. Ortiz, con Antonio Di Benedetto, con Faulkner, Proust o Joyce, entre otros. Pero a ninguno Sarlo le atribuye una importancia ni remotamente próxima a la de Borges en la trayectoria y en el destino como artista de Saer, digamos. Y a veces se tiene la impresión (como en el capítulo 2 de Zona Saer, por ejemplo) de que el peso dramático, extremo, que, según Sarlo, Borges ha tenido para Saer se presenta como una evidencia o un hecho, por una parte; y que, por otra, al mismo tiempo es una proyección de la importancia que Borges tiene para Sarlo como su lectora ferviente y, a la vez, como arquitecta de una imagen determinada y propia de la literatura argentina. Uno podría conjeturar que Sarlo dispone no solo de los textos de Saer y de Borges, comparados una y otra vez, y de un puñado de anécdotas y dichos conocidos, sino además de testimonios 
únicos y directos del propio Saer sobre una fijación temerosa, más o menos obsesiva, más o menos torturante, con la cuestión Borges (no otra imagen se desprende de las elecciones conceptuales y retóricas de Sarlo). Pero Sarlo no nos permite preferir una conjetura como esa, ni siquiera, imaginemos, mediante un escueto "me consta por boca del propio Saer que..." (y sabemos que Sarlo ha narrado poco, pero más de una vez, anécdotas personales con Saer). ${ }^{10}$ En cambio, creo que, respecto de la cuestión Borges, Sarlo hace apuestas de lectura tan atractivas como difíciles de adoptar. ${ }^{11}$ Por razones de la economía de esta exposición voy a referirme a dos lecturas que están en el mencionado capítulo 2 de Zona Saer: la primera es el uso de la tesis de Harold Bloom como una especie de ley general de las relaciones clave entre grandes escritores, y según la cual Saer habría estado obligado, como Borges con José Hernández, a "hacer el duelo y pelear un duelo", a entablar "la batalla" nietzscheana "entre iguales fuertes, entre padre e hijo" (Sarlo, Zona Saer 29). No estoy seguro de la conveniencia de extender una figura como la de la ansiedad de las influencias, pensada para un canon determinado de poetas norhemisféricos eminentes, a la relación de un escritor contemporáneo con alguien como José Hernández. Por lo demás, hay un minué táctico o confuso en esas páginas de Sarlo, porque el espacio a liberar que ocuparía Borges — si de una lógica de juego de las sillas, digamos, se tratase-, no es el de Hernández, sino el de Lugones, que es la firma que habría que señalar si se quisiera proponer que Borges peleó o batalló con alguien, como Saer contra algunos novelistas del boom (la imagen de Borges en duelo con Hernández no es una imagen de Borges, pero es una imagen borgiana, y tal vez también, por derivación o relevo, pigliana; como sea, parece una caricatura mordaz y anacrónica de Caras y Caretas). Lo cierto es que esa proposición puede resultarnos convincente o no, pero Sarlo la apoya con un argumento atractivo y a la vez insuficiente: una interesantísima lectura comparada del cuento "Palo y hueso" de Saer con "La intrusa" de Borges. Sin duda, Sarlo nota y analiza con sutileza las diversas conexiones que es posible advertir o establecer entre un relato y el otro, y proporciona elementos para describir y entender algunas diferencias relevantes entre Saer y Borges. Pero es difícil seguirla en la idea de que entender esas diferencias a la luz de la lectura comparada de esos dos cuentos es necesario para entender el proyecto creador de Saer o habría sido algo definitorio del proceso de elaboración de su poética. A pesar de que Sarlo aclara que el cuento de Saer es cinco años anterior al de Borges (Zona Saer 30 y 34), propone leer "Palo y hueso" nada menos que "como corrección de 'La intrusa"” (30 y ss.). Corregir, en efecto, hubiese sido batallar, ya que corregir es actuar de modo deliberado para suprimir un error o un defecto. En el estupendo análisis comparativo de Sarlo no hay tanto como para preferir la tesis de una corrección anticipada de un cuento en el otro. Sin embargo, las motivaciones de la lectura de Sarlo parecen, en cambio, claras y no son ajenas al contexto de los debates críticos en medio de los cuales la futura autora de Zona Saer leyó y escribió con denuedo y con afinadas herramientas críticas a favor de la importancia crucial y posborgiana de la obra del santafecino; quiero decir que en Zona Saer de 2016 la voz crítica que redescribe las relaciones de Saer con Borges es la misma que había protagonizado entre 1980 y 2000 los debates críticos, editoriales y culturales que permitieron redistribuir las valoraciones literarias de la era posborgiana; es decir, pensar esto implica enfocar el mismo conjunto de problemas del que forman parte las tan curiosas decisiones críticas de Sarlo respecto de Manuel Puig y de César Aira, para empezar por las firmas más destacadas. Al respecto, sigue siendo pertinente preguntarse si, entre los motivos por los que Sarlo casi no escribió sobre Puig, no habrá incidido el hecho incontestable de que Puig no solo resulta pensable sin Borges, sino, aún más, que pensar crítica e históricamente a Puig puede conducir a la exclusión por completo de Borges como precedencia, como poética influyente y circundante, o como condicionamiento alguno. ${ }^{12}$ Esta consideración es importante porque nos permitiría inclinarnos por la hipótesis según la cual Sarlo necesita adoptar y enfatizar una creencia de la vida literaria moderna que orientará sus lecturas: los avatares concretos y particulares en cuyo curso va emergiendo la obra singular de cualquier escritor importante - Saer u otros - responden a un puñado infaltable de principios explicativos de la historia literaria entre los que siempre están no solo los celos, las envidias, la competencia y las enemistades - el terror a terminar como imitador o epígono de un maestro demasiado presente, "la angustia de las influencias"-, sino además, y junto con eso, la historicidad cultural e intelectual que afirma que la tesis del conflicto con los padres, tíos o predecesores hace 
posible postular hipótesis respecto de algo tan particular e incluso excepcional como un corpus de relatos, unas cuantas novelas o el estilo único de la obra de un individuo. Preferiría, parecería decirnos el modo Sarlo de leer, no arriesgarme al error de atribuir valor máximo o muy alto a algo, ajeno a Borges, que se haya escrito en la Argentina después de Borges (porque, dado que no hay historia literaria sin intertextualidades históricas, esto implicaría arriesgarme a no contextualizar, a deshistorizar o a no historizar lo suficiente). Por supuesto, y si hiciese falta aclararlo, esa elección responde a la vez a una clara posición ideológica. En estas notas, como señalé, lo que me interesa destacar es que esa creencia, convertida en un presupuesto crítico e historiográfico, conduce a enfatizar, sin corroboraciones suficientes o con menos argumentos de los que convendría, una relación entre escritores, como la que imagina Sarlo para Saer y Borges.

Llevemos hacia los extremos algunas preguntas: ¿a alguien podría ocurrírsele que Saer se interesó tanto por los problemas estéticos de la novela principalmente a causa de la hostilidad de Borges hacia este género, o que se hizo novelista para "matar a Borges"? La exageración de mi pregunta intenta subrayar que, en este asunto de la relación con Borges, es necesario tener en cuenta que Sarlo - en medidas diferentes según el momento- lidia sin ingenuidades con ese rasgo saeriano que, no obstante, sopesa de un modo sesgado (posiblemente porque necesita hacerlo), rasgo principal entre los anatemas borgianos, como bien supo y anotó el propio Saer. La adhesión del santafecino al realismo y a la novela, a la vez que su destrato planificado contra las "tramas", fueron impulsos que desde 1960 se desplegaron en sus ficciones, ensayos y entrevistas explícitamente, de modo por supuesto controversial y con otros términos, pero también con esos dos: realismo y novela. ${ }^{13}$ Búsqueda problemática, obsesiva e inconformista de un modo propio de representación de lo material en una narración extensa en prosa, durante la que Saer por supuesto se ocupa de Borges, claro, pero sobre todo se aplica a reinventarse una tradición copiosa, cuya primera gran firma es a veces Cervantes, pero otras veces Balzac; conviene tener en cuenta no solo las ocurrencias de Saer sobre la obsolescencia de la novela burguesa decimonónica, sino también el interés entusiasta con que citaba a menudo el modo en que Eric Auberbach había repensando el dilema de "la representación de la realidad" desde Homero hasta Proust, pasando centralmente por la novela realista francesa del siglo XIX; basta recomenzar, al respecto, releyendo ese ensayo de 1972 que Saer tituló “Notas sobre el Noveau Roman”, basta ver todo el valor de autodescripción anticipatoria y de plan que tienen esas pocas páginas, para no sobrevaluar el peso, sin duda innegable, que la figura y el arte de Borges han tenido en Saer (El concepto 177 y ss.). La idea de cierta equivalencia entre la novela y la novela realista del siglo XIX, que Saer repite en declaraciones y ensayos (pero no en sus novelas), y que Sarlo adopta cuando lo lee, parece prescindir de las historizaciones clásicas del género (como la de Bajtín, por caso); es en ese sentido una idea de realismo y de novela historizable, es decir, históricamente situable, por supuesto, pero, en cambio, muy discutible teórica e historiográficamente hablando, como lo señalaba magistral e irónicamente Susan Sontag:

La prosa narrativa extensa denominada novela, a falta de un mejor nombre, aún ha de sacudirse el mandato de su propia normalidad tal como se promulgó en el siglo XIX: relatar una historia poblada de personajes cuyas opciones y destinos son los de la presunta vida real corriente. Las narraciones que se desvían de esta norma artificial y cuentan otra clase de historias, o parecen no contar ninguna, se inspiran en tradiciones más venerables que la del siglo XIX. (101)

Desde sus primeros cuentos - algunos tonal y hasta temáticamente borgianos, sin duda- la conexión imposible que seriamente Saer persigue establecer entre narración y experiencia real está muy lejos de la concepción borgeana de la literatura y, a la vez, no puede explicarse como efecto de una supuesta necesidad imperiosa de diferenciarse severamente de Borges, en tanto expediente imprescindible que permite encontrar una poética propia. Creo que, en este sentido, es preferible no obligarse a adoptar, sino solo selectivamente, lo que surge de la lectura de la sospecha (nietzscheana, freudiana, bourdieana o sociológica), que es siempre la conjetura sobre las manifestaciones del artista como artimañas, estratagemas, segundas intenciones no declaradas e, incluso, no deliberadas: las contadas disputas mordaces o fastidiadas de Saer contra Borges, sus diferencias de gusto y sus desacuerdos son también eso, desacuerdos, y, en ocasiones, el motivo principal 
por el cual Saer las hace explícitas puede no ser atacar al gran predecesor para destronarlo, sino contradecir ciertas ideas y sobre todo defender otras, las que prefiere con arreglo a su biografía de lector, a sus gustos y a otras motivaciones. ¿Diferenciarse radicalmente de Borges se contó — tanto o más que su regular e intensa admiración por novelísticas como las de Di Benedetto, Onetti, Faulkner, Kafka o Butor- entre los motivos principales para que, nada más ni nada menos, Saer eligiese la novela y el realismo en lugar de otras poéticas y géneros ${ }^{14} \mathrm{Si}$ las insistencias de Sarlo acerca de Borges como un elemento determinate pueden provocar preguntas como esa, es, precisamente, porque ella descarta otra conjetura que entreveo preferible: no parece que Saer necesitase tanto diferenciarse de Borges, menos mediante maniobras más o menos espectaculares y figurables como un crimen extremo, pues, si bien no sé si en 1960 Saer ya era Saer, lo cierto es que ya era lo suficientemente distinto de Borges. El día de 2016, cuando visitó el programa literario de la televisión estatal argentina para hablar de la flamante aparición de Zona Saer, Sarlo dijo al aire que, mientras en los primeros relatos de En la zona - su primer libro, de 1960-, Saer "lleva su tributo al altar borgiano", en el último relato, "Algo se aproxima", "ya no tiene nada que ver con Borges". ${ }^{15}$ Conviene precisar que En la zonaconsta de catorce cuentos, y que por lo menos otros cuatro y no solo el último - "Solas", "El asesino", "Transgresión” y "Tango del viudo" - tienen mucho de borgianos (un par ya suenan bien saerianos; en algún otro, las principales resonancias literarias, si las hay tan identificables, no remiten a Borges).

Sarlo siempre se interesó por leer en la prosa de Saer una visión del mundo, de la subjetividad y de la experiencia radicalmente escéptica, una filosofía inequívocamente "pesimista”; ${ }^{16}$ en los años 2000 , más o menos después de Lugar, ese interés fue ganando terreno en sus ensayos sobre el santafecino en detrimento del análisis pormenorizado de sus procedimientos, y Sarlo dirigió más intensa y extensamente su mirada lectora sobre el sentido metafísico de las historias narradas, de las situaciones representadas, de los dilemas de los personajes, de las encrucijadas y malentendidos, y de los destinos que los atravesaban; es casi como si, veinte años después, hubiese tomado un título como el de Gramuglio cuando escribió sobre Elentenado, "La filosofía en el relato" (1984), como plan de lectura y relectura. ${ }^{17}$

Sin embargo, la característica principal y recurrente de la lectura sarliana de Saer, que, tras lo que anotamos antes, sería en conjunto una lectura (anti)borgianamente orientada, no reside en su impecable y, a veces, conmovedora descripción de las ideas de Saer contenidas en sus escritos, sino en lo que llamé su formalismo. Restricción orientadora u orientación restrictiva, se trata del impulso regular de una lectura que reside en la articulación de ciertas constantes: técnica, intertextualidad y valor. Sarlo parece razonarlas siempre interdependientes, correlativas, como las caras bien facetadas de una pieza pulida sin el más mínimo apuro ni torpeza. Acabamos de ocuparnos de la segunda faceta, al concentrarnos en Borges, porque es Sarlo, por supuesto, la que jerarquiza esa influencia por sobre todas las demás. Respecto de la tercera faceta de la articulación, Sarlo sostiene un juicio acerca del valor máximo de la obra de Saer, que es, según insiste, "perfecta", y si, por una parte, esa perfección suena indudablemente como la consecuencia de un logro formal para el que ha resultado decisivo el "ajuste de cuentas con Borges", al mismo tiempo la perfección puede entenderse, a la inversa, como una condición, como el resultado del ejercicio único de un artista superlativo cuya excelencia estaba madura casi antes de que comenzase a escribir: "[Saer] es un escritor formado que termina su formación en sus tres primeros libros, fórmula paradógica que, sin embargo, es exacta. Responso no se podría hacer mejor" ("Vidas rotas" 39).

Entonces, se hace un enfoque en la forma como una técnica artística (poética, narrativa) nueva, singularísima, y en su funcionalidad, es decir, en la productividad semánticamente recuperable determinable - de ese hallazgo formal. La "marca Saer" es para Sarlo "el ajuste asombroso de una sintaxis tan intrincada como límpida" combinada con una "capacidad perceptiva [...] que es poética porque tiene el don de lo concreto y lo material" (Escritos 305). Esa forma que "pide una lectura lenta" (308) porque es característicamente compleja y difícil, ${ }^{18}$ compone un mundo de ficción y "una sociedad de personajes" (Escritos 315; Zona Saer 79), entonces, cuyo sentido decidible (es decir, también intrincado 
pero límpido) se produce mediante "la irrupción de lo metafísico", una "metafísica negativa” y drásticamente "pesimista" que tiene un eje, "la condición mortal", y que resulta así definitoria de lo humano. En el final de "Lectura sobre lectura", el último ensayo sobre Saer que publicó en Punto de Vista, Sarlo lo sintetiza de este modo:

Saer es un narrador irónico, un metafísico sin metafísica, cuyas preguntas ni siquiera pueden ser formuladas, sino que emergen como restos de algo fragmentado y asordinado que ya no encuentra su discurso. Un hombre que reconoce la inmanencia del mundo. El persistir terco de la materia y su corrupción inevitable son formas de una experiencia de la angustia que clava su astilla en los momentos más luminosos. No hay dioses ni se abre el camino a una visión reconciliada, a pesar de la belleza, a pesar de la escritura. (48)

"Narrador irónico", "escritura" de una "belleza" de lo "fragmentado y asordinado que no encuentra su discurso", esto da lugar a un modo definido de ver el mundo. Sarlo ha sido desde el principio muy clara al momento de exponer esa correlación formalista entre técnica y significado, mediante una sintaxis que acude a menudo a la linealidad de la sucesión causal: son "los leves desplazamientos de perspectiva" en Nadie nada nunca los que restan linealidad y proporcionan en cambio "espesor" a "lo que en la novela se cuenta", que no es una convencional serie de peripecias, sino "los estados del presente [...]. El espesor resulta, también, de las formas en que se escribe, de manera cada vez más expandida, el mismo estado del presente". "Saer construye nuestro peripecia para que nos sea posible captar el tiempo" (Escritos 316; énfasis nuestro). Más aún, la lectura sarliana de Saer resulta especialmente reveladora de su pertenencia a la conflictiva pero estrecha intimidad histórica entre los formalismos y la crítica de la ideología, como sucede en toda la poderosa tradición teórica en que se ubica Sarlo, desde la teoría rusa del extrañamiento hasta el plural barthesiano: "Nadie nada nunca - escribe- propone algo así como una paradoja de la ideología: el movimiento solo puede ser percibido cuando, descompuesto en sus momentos sucesivos, estos se convierten en estáticos" (Escritos 282, 283). Los cambios de perspectiva, la descomposición de lo representado (la sucesión y lo extenso) por el recorte reiterado de sus unidades y elementos, la focalización en cada fase o detalle — con su efecto de detención -, el "sistema de sucesivas expansiones" de la misma serie de cuadros, la ampliación de la frase mediante intercalaciones que presionan sus límites, la repetición y la postergación narrativa, en suma, "esta forma de la multiplicación” (Escritos 285), es decir, el tejido de las técnicas, producen precisamente la representación de un mundo desintegrado e inabordable, es, por tanto, una crítica de algunos de los principales presupuestos de la ideología: totalidad, unidad, identidad y cognoscibilidad. Como en el final de su texto sobre "La ocasión", para Sarlo "la literatura de Saer habla, bellamente, de la imposibilidad" (Escritos 288; énfasis nuestro). Incluso, cuando se refiere a la decisiva relación del arte narrativo de Saer con la poesía, esta se presenta en términos inequívocamente formalistas: es "precisión de registro" y "ritmo" (Escritos 316). Por supuesto que podríamos disentir con numerosos detalles u omisiones de la lectura de Sarlo, pero es preciso señalar que, en el terreno de lo que interroga y describe, es no solo valiosa, sino además imprescindible; Zona Saer contiene algunos de esos momentos sin duda magistrales de la inventiva crítica de Sarlo: respecto, precisamente, de la vinculación con la poesía, cuando propone y explica, releyendo a la vez a Barthes, la tesis según la cual "Saer expande el haiku"; o cuando explica cómo la política, decisiva en las novelas de Saer, "tiene un carácter interno a la ficción" "no es un tema", sino "una Causa" que "hace la trama" (64-65). Podemos tentar, sin embargo, otra inquietud: ¿es solo eso lo que efectúa la prosa de Saer? ¿En los modos, en los ritmos y en las flexiones de la enunciación narrativa de su prosa hay siempre efectividad, siempre concordancia entre la forma y la voz, siempre un encuentro entre los efectos semánticos de la composición y los impulsos por los que una subjetividad rara (apuntemos, apenas, rara) se obsesiona con la materia de las palabras y las cosas? O, si se quiere, ¿las "proeza[s]" (Escritos 300) de la forma siempre funcionan, es decir, terminan de un modo u otro por agregar confirmaciones de un ismo idiosincrásico y corroboran esa crítica saeriana de la ideología por medios narrativos originales que Sarlo sintetiza bajo la palabra pesimismo?

Aunque había escrito de modo elogioso sobre El limonero real en 1976, el primer texto crítico importante de Sarlo sobre Saer es “Narrar la percepción”, que se publicó en la revista Punto de Vista, en 1980, a propósito 
de la aparición en México de la novela Nadie nada nunca. Ese ensayo y "La condición mortal", aparecidos en la misma revista en 1993 tras la edición de Lo imborrable en Buenos Aires, son los dos títulos más importantes de Sarlo sobre Saer (Escritos 281-285, 289-295). ${ }^{19}$ Allí están no todas sus ideas sobre la obra del santafecino, pero están sin duda las más importantes e influyentes. Lo más sarliano de Sarlo en todo lo que escribió sobre Saer está concentrado en esos dos textos breves: ellos reúnen sus principales descubrimientos e insistencias, y algunas de sus más logradas formulaciones, especialmente en lo relativo al modo saeriano de casi inutilizar la distinción entre describir y narrar (de la que Sarlo, no obstante, parece no desprenderse nunca), cuando se trata especialmente de la representación espacializada y descompuesta del tiempo, del presente, del movimiento y de la discontinuidad material y perceptual de lo real y de la subjetividad. Pero, al mismo tiempo, de un ensayo al otro pasamos del análisis crítico a una especie de confesión de Sarlo acerca de las perplejidades que le producen las decisiones de Saer, en especial dos: la estabilización de los personajes y su creciente importancia como entidades y motivaciones narrativas, sobre todo a partir de la concatenación de la historia narrada que Glosa efectúa como analepsis respecto de Nadie nada nunca (en Glosa, de 1986, nos enteramos de que el Gato Garay y Elisa, cuya historia había sido contada en Nadie nada nunca —editada en 1980—, están a punto de ser secuestrados y desaparecidos por el ejército); y la composición de un narrador que, si bien no es por completo y sin más asimilable al narrador omnisciente, sin duda sabe demasiado en comparación con los libros anteriores a Glosa, y repone en la obra de Saer una voz de la narración más integrada, no tan fragmentaria ni plural, como en Cicatrices o en Nadie nada nunca, y menos alejada de las convenciones de la enunciación narrativa; ${ }^{20}$ en particular, este narrador estimula la mirada extrañada de Sarlo porque adelanta en futuro algunos destinos y sucesos de las historias y personajes, y porque revela en pasado el final de dos personajes de una novela anterior. No hay duda de que Sarlo dramatiza la inquietud que le causa la presencia en Saer de decisiones o giros de su poética que a primera vista resultan discordes con una determinada expectativa. Hay un punto extremo de esta estrategia confesional en una sola página de "La condición mortal"; esta comienza cuando Sarlo, refiriéndose a la línea de Glosa que agrega un final a Nadie nada nunca, afirma que

una sola frase de Glosa me obliga a releer Nadie nada nunca de un modo en que antes no suponía que podía releerlo: para ver qué hubo en ese pasado, en ese mes de febrero durante el que transcurre la novela, que yo no vi, que Saer probablemente no ocultó pero tampoco dijo. (Sarlo, Escritos 294)

La primera persona del singular evita el error (pero permite postularlo), porque en efecto es muy difícil imaginar cómo esa u otra frase de la novela de 1986 podría obligar a alguien, a quien fuese, a algo. Por supuesto, de hecho Glosa ha sido leída de muchas maneras, la mayor parte de las cuales posiblemente ignoremos; una que conocemos es la de los lectores que hasta el presente no han leído Nadie nada nunca, o la de quienes comenzaron en 2005 con La grande, de adelante hacia atrás (como Saer cuando ordenó la edición de sus Cuentos completos) y todavía no han llegado a Nadie nada nunca, pero sí a Glosa; o los que tienen bien presentes las dos novelas, pero leyeron, como procedimiento narrativo en nada desconcertante, que la historia narrada en Nadie nada nunca podría encontrar un final como ese y en un libro posterior donde "la zona", es decir los lugares, algunos tiempos cronológicos de la ficción y los personajes, fuera en gran medida la misma. Ciertamente, son muy pocos los lectores de Saer (como los de tantísimas obras, obviamente) que lo leyeron en el orden de publicación de los libros. Por supuesto, pocos críticos habrá que sepan evitar siempre la imagen que unifica a todos los lectores efectivos y posibles de un texto en un modo más o menos normalizable de leer - más si es un modo escolarizable de hacerlo, o si es el propio, o todavía más si es el propio y coincide en gran medida con el modo de leerse del autor-. Tendemos a suponer que se lee de un modo determinado, trátese del orden en que se pasa de un libro del mismo autor a otro o de la manera de interpretar el sentido de una novela. ¿Puede decirse que esa obligación en la que Glosa puso a Sarlo procede de un protocolo crítico más o menos universitario o especializado (relativo a la importancia que se le dé a las decisiones deliberadas del autor, como contar el final de una novela en otra 16 años posterior), un protocolo empero ni más ni menos pertinente que cualquier otro o que cualquiera de las secuencias contingentes de las lecturas a las que conducen 
el azar, las casualidades o la ajenidad de gran parte de los lectores con los protocolos críticos? En todo caso, la pregunta es posible porque es la propia Sarlo la que se previene contra la eventual objeción de academicismo respecto de esa relectura que experimentó obligada, en un movimiento retórico bastante espectacular y que bien podríamos conjeturar denegatorio:

Se dirá: la literatura de Saer soporta mal esta suerte de re-lectura, alejada de los protocolos críticos contemporáneos. No lo creo (y en lo que concierne a los "protocolos críticos", no quisiera que una tendencia de la ideología académica, por más venerable que sea, me impida leer lo que leo). (Sarlo, Escritos 294)

Ese juego retórico parece destinado a relativizar las propias perplejidades que Sarlo ha confesado respecto de esta especie de reencuentro de Saer con elementos de "la gran tradición decimonónica", y a replantearlo como parte de las "nuevas condiciones de narración" que Saer reconstruye porque conoce bien, entre otras cosas, "la imposibilidad de la narración clásica”. De modo que, paradojalmente, Saer escribe así, como en Glosa - con personajes reconocibles que permanecen, y con un narrador que sabe mucho más que ellos y ya no menos-, porque apostó a "la imposibilidad de seguir narrando como hasta las primeras décadas del siglo XX" (Sarlo, Escritos 294-295). En las citas precedentes reordené algunas de las frases de Sarlo para que se vea la contradicción que su texto expone, con el propósito de disolverla mediante un orden de los argumentos y las proposiciones diferente del que les doy acá.

Estas perplejidades que Sarlo esperó hasta 1993 para confesar deben encuadrarse precisamente en el decurso de su lectura de la obra, que, en efecto, siguió la cronología y el orden de la publicación. En Nadie nada nunca Saer había llevado al extremo la descomposición de un mundo que venía explorando en las formas de El limonero real y sobre todo en La mayor (1976), un mundo cuyos pedazos, nos repetía un personaje, no se podían juntar desde Cicatrices (1969); sin duda, pudo parecer que la forma saeriana y solo saeriana de la narración, y particularmente de la novela, alcanzaba su ápice en esa fase de su recorrido, durante la cual resultaba decisiva la economía extrema de una voz narrativa despojada de atributos, ascética de saberes, ajena a las vanidades de la enunciación yoica o cultural y, por supuesto, a la omnisciencia. Seguramente, no resultaba precipitado ni prematuro dar por hecho que en Nadie nada nunca, entonces, Saer ya estaba logrando el mayor alcance del principio que regía su poética: una adhesión radical al escepticismo materialista menos complaciente y al modernismo estético más negativista. Ciertamente, algunos pocos ensayos del propio Saer, y algunas entrevistas, contribuían a que Sarlo, entre otros, fijasen para siempre esa imagen como descripción y también como expectativa. Al respecto, el siguiente fragmento (un ejemplo entre muchos) es de una entrevista de junio de 2015:

“¿Cuál es el primer recuerdo que le aparece si le digo 'Saer'?”, le pregunta LA GACETA a Sarlo. La ensayista se toma unos segundos y se lanza: "Me acuerdo vagamente de la lectura de Nadie nada nunca, durante la dictadura militar. Se publicó en México. Sigue siendo mi novela favorita de él. Aunque sé que no es su más grande novela, que supongo es Glosa”. (Duchini)

La lectura saeriana de Sarlo resultó de las más influyentes sin duda porque su recorte no solo fue selectivo y estuvo teóricamente orientado (formalista), sino porque, además, en el interior de esa orientación fue un recorte acertado: para decirlo con los términos clásicos que resultan aquí los más apropiados, Sarlo buscó y seleccionó, para ponerla en el primer plano de su lectura crítica, la lectura dominante, "el principio constructivo". Reseñó La ocasión apenas salió en 1988, y recién siete años después de Glosa decidió mantener la valoración máxima que venía atribuyéndole a Saer en el mismo texto crítico en el que mostraba en primera persona toda la perplejidad que experimentaba ante los cambios que había introducido aquella novela de finales de 1986. Otros lectores, lectores de otras generaciones y grupos, ya leímos Glosa de otras maneras, ajenas al dilema que Sarlo encontraría en "La condición mortal". No recuerdo que los lectores de mi generación con quienes solía conversar de libros nos sintiésemos obligados a releer Nadie nada nunca tras el párrafo en el que Glosa nos entera del destino de Elisa y el Gato. ${ }^{21}$ En 1987, Jorge Panesi, además de asociar El limonero real a la resonancia de Juan Rulfo y su impronta, mencionaba, lejos de cualquier idea de perfección, ciertas torpezas constructivas de Nadie nada nunca (especialmente respecto del injerto del texto de Sade en 
el relato), y proponía que Glosa era una especie de tour de force de La mayor. Panesi encontraba, creo, en la prosa cuasiconversada de Glosa una exploración amplificada de las posibilidades del habla sostenidas por la voz de Tomatis, especialmente en "La mayor", el primer relato del libro de 1976: como si la máquina de la sintaxis proustiana usada para experimentar en español con el soliloquio, con el monólogo interior o el fluir de consciencia, con el diálogo, con la glosas conversadas de conversaciones y de glosas de conversaciones, no fuesen más que el medio - el terreno- de un teatro de todas las incertidumbres de la subjetividad que habla en lo escrito y a la vez de la subjetividad de quienes leemos. Panesi y tantos otros lectores de Saer estábamos bien al tanto, por supuesto, de la sospecha crítica en la que desde antes de los años setenta se encontraba el "realismo" en los ambientes artísticos e intelectuales de vanguardia en Buenos Aires. Sin embargo, no recuerdo que experimentásemos ni que hubiésemos conversaso sobre ninguna incomodidad con el narrador inventado por Saer para Glosa, ni con sus saberes, ni con su relación con los hechos futuros de la historia. Más bien, escuchábamos en ese narrador las consabidas resonancias de los tonos socarrones de Tomatis y de otros narradores previos de Saer, los momentos de parodia de registros y hablas sociales más o menos identificables, el equilibrio que encontraba la escritura para tensar sin disonancia ni ripio, más bien con una rara comicidad, esa tan particular coloquialidad con la extenuación sintáctica arrastrada desde La mayor, el paso frecuente y magistral del relato hacia la melancolía... En Glosa leíamos la afección emocional y física que se confundía con (que era a la vez) el efecto narcótico, cautivante y perturbador de la cadencia poética del texto. Sería insensato ignorar el acierto de Sarlo cuando piensa "La condición mortal" como un problema narratológico, estético y lógico que rige la arquitectura del ciclo saeriano y, a la vez, su relación con la novela y con la historia moderna del realismo literario (en efecto, mientras no se nos esté narrando un episodio de la vida de Zeus, digamos, la condición mortal obviamente es la base del verosímil realista de la categoría "personaje" y puede serlo, como en este caso, de todo lo que sepa o ignore el narrador). La condición mortal es, entonces, también en Saer, por supuesto, no solo un tópico metafísico, sino además una motivación central de las posibilidades de la puesta en intriga y de la composición textual. De tal manera, Sarlo conduce su lectura de modo que uno de los nudos saerianos que más parece haberla incomodado también se encuadre en el valor de la forma y su función, legitimadas por una precedencia intertextual prestigiosa: como los personajes de Faulkner (cuyos lectores "también forman un círculo de entendidos"), los personajes de Saer, "esa sociedad santafesina que, como una tribu, se mueve en las mismas calles, bares, patios", están ahí para oponer una "continuidad [...] al instante y al olvido", pero son sobre todo uno de los "principios constructivos de su obra", "son invariantes narrativas". Los lectores podríamos esperar caracteres, personajes con historias y destinos, peripecias, finales felices o desdichados; pero los lectores de Saer, parece, hubimos de entender que lo primero que su obra daría eran formas, tropos o convenciones reinventados por la forma: Tomatis, la principal invariante narrativa, "es una necesidad formal: esperamos la ironía y la ironía es Tomatis" (Sarlo, Zona Saer 80, 84-86). ${ }^{22}$

El eficaz formalismo modernista de Sarlo no es un formalismo cerrado ni ciego; su interés por la relación entre técnicas y formas no es formulístico ni algebraico, mucho menos abstracto, sino histórico, hermenéutico y ensayístico: en la línea de algunas de las más intensas tradiciones argentinas de la polémica intelectual, lee como una crítica de la literatura, no como una catedrática. Posiblemente sea también por eso que su formalismo es, además, omnívoro y — aun enunciado por una voz lectora conmovida - es un formalismo inconmovible.

¿Cuánta razón tiene, entonces, la lectura de Sarlo, sus argumentos y sus juicios sobre la obra de Saer? De las posibles respuestas que no proceden del mismo juego de presupuestos de Sarlo que estoy describiendo, descarto la de eso que ella misma llamaba a veces el relativismo cultural y que uno prefiere identificar con el politicismo de la crítica universitaria radical más o menos dominante: no habría modo de validar ni de invalidar las razones de Sarlo sobre Saer que no respondiera a intereses (políticos) situables; en tal sentido, no sería más preferible ni fundamentado afirmar que Saer es un gran escritor según los argumentos de Sarlo, que aseverar en cambio que se lo considera como tal a causa de la insistencia estratégica prolongada de la voz de Sarlo (y de algunas otras), de su resonancia y su eficacia persuasiva (por aproximación, hablo de un aspecto 
de las escrituras críticas fuertes que en la Argentina solíamos problematizar en torno de firmas como la de Viñas, o la de Piglia: aunque no sepamos si las razones de Piglia sobre la literatura argentina son verdaderas, fue posible experimentarlas cautivantes, ingeniosas como un alejandrino bien acentuado o inflamables como un panfleto persuasivo y perentorio). No hay mucho que indagar en la respuesta radical porque remite casi por completo a una sociología de las pujas y los tráficos editoriales, críticos y universitarios, de los que resultan la consagración o la canonización literaria. En cambio, estoy intentando dejar por lo menos apuntada otra clase de respuesta, una mirada sobre las lecturas, sobre los efectos de lectura. En este terreno mi elección crítica aquí es al mismo tiempo teórica y generacional: un modo de la experiencia de la lectura literaria, asociada a ciertos estilos críticos, prosas teóricas y filosofías, en los que reconozco más a mi generación (o a parte de ella, claro) que al modo Sarlo de leer, pero también en los que veo vestigios de las experiencias de lectura de lectores de Saer que no parecen muy presentes en los presupuestos de Sarlo, y que forman parte de otros círculos de entendidos en otras cosas: lectores docentes, estudiantiles, escolares; legos, lectores que no son ajenos a las responsabilidades de la tarea del crítico profesional ni del intelectual crítico, lectores corrientes muy próximos a esa ambigua, taimada, resbaladiza figura que Samuel Johnson, Virginia Woolf y George Steiner trataron y destrataron como the common reader.

Para reformularlo en pocas líneas: Sarlo extrema y explora una confianza firme y paciente en un enfoque semiótico, busca el significado y el sentido, y el modo en que está compuesto el significado y producido el sentido, y, en cambio, parece no interesarse mucho en el efecto; con efecto apunto a lo que (utilizando a Bajtín) podemos llamar el lector textual, al mismo tiempo que a la instancia de la lectura que le es inmediatamente contigua, esto es el sujeto en-trauma o en-desubjetivación a causa de la lectura, una instancia donde precisamente es el sentido - “pesimista”, optimista, apático...: cualquier sentido- el que siempre está en falta porque quien lee queda interrumpido y resta suspendido en un cierto grado de vacilación insuprimible. ${ }^{23} \mathrm{Si} \mathrm{la} \mathrm{literatura,} \mathrm{como} \mathrm{lo} \mathrm{sostiene} \mathrm{una} \mathrm{vasta} \mathrm{biblioteca} \mathrm{del} \mathrm{pensamiento} \mathrm{contemporáneo,} \mathrm{emerge}$ únicamente en la experiencia donde el lenguaje queda imprevistamente sustraído de sí y condenado a su distancia mínima, pero irreductible, respecto de todo sentido decidible, el trabajo crítico de Sarlo parece darnos a entender que no es ese el problema del que deba, pueda o quiera ocuparse. No se trata de que su discurso crítico suene ajeno al apasionamiento de la lectura como experiencia que toca a la primera persona de la crítica ni, menos, que rechace las manifestaciones de la subjetividad — que en su caso es a menudo intensa, franca, directa-. La cuestión reside más bien en que Sarlo elige leer para entender, es decir, para explicar y establecer una interpretación; de modo extremadamente formulario, digamos que Sarlo lee así: la singular forma narrativa saeriana da a entender de modo complejo, pero decidible - mediante lo que le hace al idioma y a la imaginación del tiempo, del espacio y de la condición mortal一, que no podemos entender el mundo, ni la subjetividad, ni la experiencia, si los hubiese. No se trata de que esa parcialidad (el diccionario partidista y deportivo es del gusto de Sarlo) pueda ser impugnada, sino, más sencillamente, de que debe quedar señalada, si lo que queremos es entender el modo Sarlo de leer literatura como una preferencia que excluye a otras. Entonces, lo que se gana con esa elección y al precio de sus límites es una descripción precisa y por momentos inmejorable de la obra de Saer como creación de un modo único de representación, un estilo de escritura en prosa con una orientación expresiva y una visión del mundo problemática pero definida y decidible; Saer es "el mejor", parece ir diciéndonos Sarlo, debido a que la eficacia semiótica de ese modo saeriano de la representación narrativa es, tal como la logra y la sostiene, máxima; a su vez, lo representado por ese modo saeriano singularísimo de representar es la experiencia toda como "incertidumbre", los estados y la condición misma de "lo incierto" en todo lo que pueden alcanzar las palabras y las percepciones. Y sobre eso no hay incertidumbres: para Sarlo lectora de Saer, o para el lector que imagina para Saer, la incertidumbre saeriana es una certidumbre o poco menos. No habrá estados remanentes de indeterminación acerca de la indeterminación saeriana, ni residuos de vacilación incesantes como efectos materiales de lo irreal sobre la subjetividad de quien leyó. ${ }^{24}$ Debido a que nos conduce "la destreza de Saer", estamos sin dudas en el territorio de todas las dudas, sin vacilaciones en el universo de la vacilación, sin incertidumbres en 
una singularísima, densa y dificultosa semiosis literaria de la incertidumbre; estamos ante la codificación lingüística, imaginaria y poéticamente más sofisticada de un intenso y regular "pesimismo" acerca de lo real y de nuestras posibilidades de acceder a lo real. Para Sarlo, el efecto que interesa, el logro de esa forma perfecta, en tanto lo es de la representación, parece ser de tenor intelectivo: una "metafísica sin metafísica" o una "metafísica negativa" ("Vidas rotas" 39) que se traduce, no obstante, en un cierto haz de convicciones sobre el tenor de lo real, propuesto por medios literarios y no explicativos, por argumentos y no argumentaciones. ${ }^{25}$

Con ocasión del escándalo que en el 2007 protagonizaron las autoridades de la Facultad de Filosofía y Letras de la Universidad de Buenos Aires al negarle a Sarlo la designación como profesora plenaria que recomendaba un jurado internacional, el reconocido crítico porteño Daniel Link compensaba la generosidad merecida del elogio señalando algunas disidencias. Me interesa esta: "Podría señalarse, también, que Sarlo es incapaz de leer, en ciertos fenómenos de la cultura contemporánea, el componente 'libidinal' que contienen”. Recuerdo perfectamente que cuando lo leí experimenté un acuerdo inmediato con el juicio de Link y pensé al mismo tiempo que sin dudas el símil psicoanalítico era acertado y a la vez insuficiente. Creo que era eso mismo, con otra figura, lo que me decía un novelista argentino quincuagenario, también atento y agradecido lector de Sarlo, hacia 2016: Sarlo nunca lee justamente "el punto ciego", eso que a nosotros siempre nos interesa de la literatura, eso que nos toma y es capaz de mantenernos discutiendo una novela noches enteras. La poeta María Negroni propuso alguna vez que "la poesía es una epistemología del no saber". Lo que no estaría atestiguado en el modo Sarlo de leer a Saer es ese estado de inestable suspensión en el que queda el lector que - entregado a la poesía del relato - no sabe si sabe o si en cambio ignora que podamos saber y tener, del mundo y de nosotros mismos, nada o en cambio algo. Sarlo posibilita más bien un lector esforzado que explora con receptividad la selva espesa de la lenta complejidad saeriana hasta que entiende, y ese entendimiento se abre paso hasta presentar un margen de duda bajo, es decir, poco relevante, aunque lo que se entiende sea que, según Saer, no podemos saber ni tener, del mundo, nada. Es posible conjeturar, entonces, que ese "punto ciego", que ese "componente libidinal" (el objeto-causa del deseo siempre resta y se sustrae al sentido), es desde 1980 el límite mismo de la lectura de Sarlo que, como digo, posibilita a la vez sus alcances siempre propios, definidos y, como todo punto de partida, ineludibles, polémicos e influyentes.

Voy a excederme y simplificar con una comparación que tiene, no obstante, algo de apropiada: Sarlo parece haber descartado leer a Saer como tantos hemos leído a Beckett. Un artista que repite incansablemente y de muchos modos que su empeño incesante y retomado incontables veces conduce siempre al fracaso y a la vez a lo contrario, es decir que "hay que seguir", pero que, además y simultáneamente, actúa una y otra vez tal empeño mediante una poética que incluye siempre la formación mal calculada de efectos (no de significados) poéticamente desconcertados y hasta ajenos a ese "pesimismo" que se dice radical y definitivo y que, por supuesto, rige los temas de los relatos y los estados y destinos de los principales personajes, pero nunca, en cambio, la creciente y disforme fuerza productiva de invención y de escritura: ese narrador no hace sino proseguir, aunque no sepa hacia dónde, no deja de imaginar (aunque no sepa bien qué) ni de hacer sonar algo más, y aun algo más otra vez, no deja de escribir y reescribir. ${ }^{26}$ Ese impulso sería el que impide que en la experiencia del lector se cristalice cualquier equivalencia o correlación estabilizable entre los efectos poéticos de desubjetivación y determinados contenidos ontológicos de los enunciados escritos o de las historias narradas. Sarlo, maestra en leer comienzos, no parece haber asediado el comienzo de su novela saeriana preferida, Nadie nada nunca, esa especie de escándalo lógico que se cursa en el acto poético (no en asertos explicativos): ¿por qué el narrador continúa por más de 200 páginas, después de haber escrito esa negación taimada, sospechosa, del incipit creacionista del Génesis, es decir que "No hay, al principio, nada. Nada"? Una sencilla respuesta diría que el impulso activo del narrador "pesimista" no cesa después de ese comienzo, precisamente con el propósito de corroborar que tampoco hay nada después del "principio", casi al final: "Como en un planeta desierto, como en un desierto, no se oye nada. La playa está vacía" (Saer, Nadie nada 203). Así recomienza el anteúltimo de los quince parágrafos numerados en romanos que componen la novela. Pero, entonces, es preciso subrayar que el lector que la interlocución de la escritura está efectuando 
allí ve los trazos de una voz que - a semejanza del "río liso, dorado, sin una sola arruga" del comienzo de la novela-da para imaginar un símil extremo, de un espesor evocativo poderoso y sin duda no calculable. Ese acontecimiento poético, esa contingencia que emerge en el encuentro con la sonancia muda de "planeta desierto" y "desierto" silencioso y "playa vacía" (una contingencia que no es fatal pero sí altamente probable y frecuentemente ocurrida en cada acto de lectura de ese y de tantos fragmentos) escapa a la lectura intelectiva: no es ni negativo ni afirmativo, es decir, excluye su reducción a un aserto, porque se trata de una manifestación. La pregunta crítica que la poiesis de Saer parece pedir aquí no sería, entonces, qué dice la literatura por el modo en que está hecha (esa es la pregunta semiótica que Sarlo responde con sesgo historicista). La pregunta sería, tal vez, qué (nos) hace la literatura (y qué deshace en nosotros y de nosotros) cuando hace a la vez con el lenguaje y con la imaginación eso que no era decible ni imaginable antes de que leyésemos (pero que no pasa a serlo solo porque la hayamos leido). La irrelación con la cultura que efectúa el comienzo de Nadie nada nunca, es decir, la disyunción ${ }^{27}$ de la contigüidad entre "No hay, al principio, nada" y "El río liso, dorado" es la misma que Saer compone para el título de su “Tratado imaginario" sobre el delta del Plata: El río sin orillas—negación afirmada, afirmación negada - suspende todo juicio y es la ruina del principio de identidad y del principio de no contradicción; es la misma experiencia a cuya irreductibilidad vuelve Alain Badiou cuando señala la insuprimible "diferencia mínima" creada por la tela de Kasimir Malevich y por su título, Cuadrado blanco sobre fondo blanco (79). Si la poética de Saer se jugase — según hemos discutido por años- en Nadie nada nunca, el principio de su crítica vive —-incluso por motivos de época - en la circulación incesante entre el "No hay nada", pariente fatal de la consigna lacaniana mil veces repetida, y el "pero algo tiene lugar" que se vuelve insuprimible desde que alguien escribe la frase "no hay relación sexual" o la frase que fuese:

¿De qué se trata aquí? De la relación sexual en tanto que tiene lugar: no para desmentir a Lacan, que dice que no la hay, sino para distinguir aquello que hay (aquello que está dado, presente, disponible) de aquello que tiene lugar (aquello que no está dado, pero se da, aquello que ocurre, que sobreviene). [...] La relación en tanto que desconcierto: suspensión de la concertación y aparición de la sorpresa, interrupción definitiva o provisional [...] toda relación depende de la heterogeneidad y de la heteronomía de los inconmensurables. (Nancy 57)

\section{Bibliografía}

Agamben, Giorgio. Lo que queda de Auschwitz. El archivo y el testigo. Homo sacer III. Pretextos, 2002.

Badiou, Alain. El siglo. Manantial, 2005.

Barthes, Roland. El discurso amoroso. Seminario en la Escuela de Altos Estudios, 1974-1976. Paidós, 2011.

Bloom. Harold. La angustia de las influencias. Monte Ávila, 1991.

Bloom, Harold. El canon occidental. Anagrama, 1996.

C5N. "Guía de Literatura Argentina, por Beatriz Sarlo". Youtube, subido por Lagrimita y Morisqueta, 11 de febrero del 2012, https://www.youtube.com/watch?v=J1yi-P7u7Ok\&t=24s.

Dalmaroni, Miguel. "El largo camino del 'silencio' al 'consenso'. La recepción de Saer en la Argentina (1964-1987)”. El entenado. Glosa, por Juan José Saer, Alción, 2008, pp. 607-663.

Duchini, Alejandro. "Juan José Saer: cicatrices de una larga ausencia”. La Gaceta, 7 de junio de 2015, http://www.laga ceta.com.ar/nota/640433/la—gaceta—literaria/juan—jose-saer-cicatrices-larga—ausencia.html.

Giordano, Alberto. "El efecto de irreal". La experiencia narrativa. Beatriz Viterbo, 1992.

Gramuglio, María Teresa. "La filosofía en el relato". Punto de Vista, vol. 7, n. ${ }^{\circ} 20$, mayo de 1984, pp. 35-36.

Lacan, Jacques. Mi enseñanza. Paidós, 2007.

Link, Daniel. "Beatriz Sarlo en la encrucijada nacional. Bibliografía obligatoria”. Página/12, https://www.pagina12.c om.ar/2001/suple/Libros/01-10/01-10-07/nota2.htm.

Los 7 locos. "Beatriz Sarlo sobre Juan José Saer en Los 7 locos”. Youtube, subido por Televisión Pública, 1 de agosto de 2016, https://www.youtube.com/watch?v=ROhFEXmP7vU\&t=1374. 
Nancy, Jean-Luc. El "bay" de la relación sexual.Síntesis, 2003.

Rancière, Jacques. Politique de la littérature. Galilée, 2007.

Saer, Juan José. "Borges novelista”. El concepto de ficción. Ariel, 1998, pp. 282-290.

Saer, Juan José. Cicatrices. Sudamericana, 1969.

Saer, Juan José. El entenado. Folios, 1983.

Saer, Juan José. El limonero real. Planeta, 1974.

Saer, Juan José. El río sin orillas. Alianza, 1991.

Saer, Juan José. En la zona. Castelví, 1960.

Saer, Juan José. Glosa. Alianza, 1986.

Saer, Juan José. La grande. Seix Barral, 2005.

Saer, Juan José. La mayor. Planeta, 1976.

Saer, Juan José. La ocasión. Alianza, 1988.

Saer, Juan José. La vuelta completa. Biblioteca C. C. Vigil, 1966.

Saer, Juan José. Las nubes. Seix Barral, 1997.

Saer, Juan José. Lo imborrable. Alianza, 1993.

Saer, Juan José. Lugar. Seix Barral, 2000.

Saer, Juan José. Nadie nada nunca. Siglo XXI, 1980.

Saer, Juan José. “Razones”. Juan José Saer por Juan José Saer. CELTIA, 1986.

Sager, Valeria. El punto en el tiempo: realismo y gran obra en Juan José Saer y César Aira. 2014. Universidad Nacional de La Plata, tesis doctoral.

Sarlo, Beatriz. Borges: un escritor en las orillas. Ariel, 1995.

Sarlo, Beatriz. "El mejor. Juan José Saer (1937-2005)”. Punto de Vista, vol. 27, n. o 82, agosto de 2005, p. 1.

Sarlo, Beatriz. El mundo de Roland Barthes. CEdAL, 1981.

Sarlo, Beatriz. Escenas de la vida posmoderna. Intelectuales, arte y videocultura en la Argentina. Ariel, 1994.

Sarlo, Beatriz. Escritos sobre literatura argentina. Siglo XXI, 2007.

Sarlo, Beatriz. "La condición mortal". Punto de Vista, n. ${ }^{46}$, agosto de 1993, pp. 28-31.

Sarlo, Beatriz. "La política, la devastación”. El entenado. Glosa, por Juan José Saer, Alción, 2008, pp. 762-778.

Sarlo, Beatriz. "Lectura sobre lectura”. Punto de Vista, vol. 30, n. ${ }^{\circ} 89$, diciembre de 2007, pp. 46-48.

Sarlo, Beatriz. “Saer, Tizón, Conti. 3 novelas argentinas". Los Libros, n. . 44, enero-febrero de 1976, pp. 3-6.

Sarlo, Beatriz. Siete ensayos sobre Walter Benjamin. Fondo de Cultura Económica, 2000.

Sarlo, Beatriz. "Vidas rotas". Zona de prólogos, compilado por Paulo Ricci, Seix Barral, 2011, pp. 37-46.

Sarlo, Beatriz. Zona Saer. Ediciones Universidad Diego Portales, 2016.

Sontag, Susan. Al mismo tiempo. Ensayos y conferencias. Mondadori, 2007.

Steiner, George. Después de Babel. Aspectos del lenguaje y la traducción. Fondo de Cultura Económica, 2001.

Steiner, George. "Los tigres en el espejo". Extraterritorial. Ensayos sobre la literatura y la revolución del lenguaje. Adriana Hidalgo, 2009.

\section{Notas}

* Artículo de investigación. Este artículo, inédito, forma parte del proyecto en proceso “'Literatura' como 'lectura' en la teoría literaria, la crítica, las ficciones y las poéticas, y en situaciones de 'enseñanza', en la Argentina contemporánea”, que el autor lleva a cabo como investigador del Conicet. 
[1] Las primeras ediciones de casi todos los artículos que cito de Escritos de Literatura argentina están en la colección completa de Punto de Vista.Este es un ensayo acerca de los escritos de Sarlo sobre Saer: he tenido en cuenta algunas de las numerosas menciones del santafecino que Sarlo ha hecho cuando se ocupaba de otros temas en intervenciones escritas o en congresos, y unas pocas de sus apariciones televisivas en las que habló de Saer.

[2] Por supuesto, no ignoro ni pretendo insinuar un cierre alguno para la controversia respecto de si es posible o no la lectura (la experiencia) como una interrupción no calculable y momentánea de las determinaciones, es decir, como una desubjetivación en tanto desujeción (Agamben). Pero también me interesa advertir que la idea según la cual la desubjetivación-desujeción, nomás si se admite que se produzca, implica necesariamente un enfoque emancipatorio, libertario o edificante es un preconcepto modernista.

[3] No cuento aquí los breves volúmenes dedicados por Sarlo a Barthes y a Benjamin, porque estos son el resultado menos de proyectos personales que de propuestas editoriales, con algo de encargo, el primero, y como el resultado de una compilación de trabajos ya publicados, el segundo.

[4] Al final de Zona Saer, Sarlo narra que fue Fabián Casas (Buenos Aires, 1965) quien le dio la idea de escribir "un libro sobre Saer, como el que escribiste sobre Borges" (Sarlo, Zona Saer 119).

[5] No hace falta alejarse un milímetro de una perspectiva como la de la lucha de clases u otras similares, o en general de alguna concepción conflictivista de la vida social, para saber que — comparada con las pujas por el capital simbólico y económico en "campos" o redes corporativas como el sindicalismo, los partidos políticos, el mundo de las finanzas, los negocios vinculados a los deportes de afición masiva, etc.- las luchas del "campo literario", "artístico" o "intelectual” son un inofensivo juego de niños aun en sus momentos de mayores enfrentamientos o de censuras, persecuciones y represiones por parte del poder político o estatal.

[6] "Es curioso que se lo llame uno de los grandes escritores de la Argentina, atándolo a una geografía que es la de su ficción y la de su lengua, claro está, pero no la de su valor", anota Sarlo en "El mejor", su nota con ocasión de la muerte de Saer (1).

[7] Como ya anoté, el hecho de que Sarlo haya insistido tanto en la "perfección” de Saer responde, por supuesto, al propósito de volverlo un escritor consagrado o de valor indiscutible. Hasta donde sé, al menos Ricardo Strafacce cree, como yo, que la prosa de Saer no nos ofrece solo hallazgos e invenciones extraordinarias, sino además no pocos ripios y galicismos, especialmente sintácticos. Tales rasgos pueden tomarse o no por imperfecciones, por supuesto: en literatura y arte, se sabe, cualquier idea de perfección es casi un constructo ad hoc.

[8] Hasta su editor y amigo Alberto Díaz, según él mismo me lo contó, posaba una resignación cómica y le repetía socarronamente ese reproche extendido, cada vez que Saer le mostraba un nuevo manuscrito: “¡Siempre lo mismo, acá no pasa nada, no hay una historia!".

[9] Es francamente impactante cómo Sarlo evita interrogar Las nubes como un relato sobre la locura, mientras escribe páginas admirables sobre los locos de la novela y sobre el modo en el que el relato pone a jugar sus historias en la historia, como si todos y cada uno de esos dementes fuesen nomás funciones narrativas del principio constructivo al que sirven, un capítulo de la historia de la novela que Saer reinventa: la aventura y el viaje (especialmente en Sarlo, Escritos 300). Recordemos que la locura es un tema saeriano desde Cicatrices, por lo menos (y que había vuelto de un modo u otro en varios textos: Lo imborrable, La pesquisa).

[10] Por ejemplo, en Escenas de la vida posmoderna (144-147); y especialmente en Zona Saer (16).

[11] Seguramente, cierto sentido común sobre Borges como hito obligado, muralla insuperable o desafío desproporcionado se deba en gran medida a la habituación cultural y universitaria de voces como la de Sarlo, la de Piglia o la de Josefina Ludmer, que repitieron por años como un hecho indiscutible el peso aplastante de Borges como vara y bisagra ineludible en la vida literaria argentina y especialmente como determinación de hierro para el proyecto creador de todo escritor del que pudiésemos esperar algo de valor. Lo que es preciso excluir para poner a Borges allí es demasiado y demasiado importante. La mera mención de Manuel Puig alcanza y sobra, y eso para mantenernos en la discutible equivalencia naturalizada entre literatura y narrativa; también habría que revisar el lugar de Borges si, en cambio, tenemos en cuenta, además de la narrativa, el canon de la poesía argentina de los últimos ochenta años.

[12] Como en ningún otro momento de su trabajo crítico, lo que Sarlo ha dicho y escrito sobre Puig confirma la tenacidad y las limitaciones de su formalismo; me refiero, para resumir, a la reducción de Puig al pop art, una idea que no es completamente errónea, solo porque tiene alguna utilidad para describir la técnica, pero que conduce a Sarlo a morigerar, por ejemplo, su elogio de Boquitas pintadas como "cosas livianas aunque completamente revolucionarias": liviana es la lata de sopa, las letras de Le Pera, el folletín -en fin, los materiales - y revolucionario es el invento de una técnica que incluye todo eso en la literatura; véase Sarlo, Escritos 223-224 y C5N. 
[13] Me cuento entre los lectores de Saer que consideramos su poética como una poética del realismo, es decir, un modo singular e intencional - deliberado- de trato literario de lo real; la tesis de Valeria Sager puede considerarse en ese sentido un momento de síntesis y cierre del debate crítico sobre este tópico.

[14] Pienso en ocurrencias de Saer argumentativamente muy débiles pero reveladoras, como las que encontramos en "Borges novelista" (282-290). Aunque releer textos como ese puede mostrar que Saer pudo haber necesitado hacer, y de hecho quiso hacer, con Borges algunas cosas, más o menos corrosivas algunas, pero no tanto como ganarle un "duelo" o una "batalla".

[15] "Beatriz Sarlo sobre Juan José Saer en Los 7 locos ", véase Los 7 locos.

[16] Pesimismo y pesimista se cuentan entre las palabras más usadas por Sarlo para sintetizar la visión del mundo que ella le atribuye a la obra de Saer ( Escritos 288, 307, 310, 314, 319; Zona Saer 64, 83; "Lectura" 48).

[17] La literatura, por supuesto, supone o propone siempre una visión del mundo y de la condición humana, a veces de modo muy explícito. Esta reducción a Perogrullo no es, por tal, menos verdadera: toda novela es, en alguna medida y a su manera, una novela filosófica, ontológica, metafísica, antropológica... Me cuento entre los tantísimos que creen que la filosofía de las novelas de Saer su cosmovisión, las ideas sobre lo real que supone y propone- no es original ni novedosa (no veo nada al respecto en Saer que no se haya pensando en la filosofía del siglo XX, en el psicoanálisis, en la filosofía del lenguaje, en la epistemología de las ciencias naturales y en la astrofísica). Tampoco creo que el hallazgo de la forma perfecta con la que se puede componer verbalmente un pensamiento determinado sea un patrimonio ni una prerrogativa de la ficción literaria. Esa vasta biblioteca, que la compartimentación cultural de las escrituras llama filosofía, ha prodigado formas perfectas, capaces de cautivarnos tanto como la prosa de Saer, la de Sebald o la de Borges. El tenor poético de la literatura, a diferencia del de la filosofía, no es tal porque componga una metafísica original o no lo haga, sino porque produce (como querían Marx o Raymond Williams, entre tantos) una experiencia para la que no hay decibleimaginable alguno en el entero territorio de la cultura disponible.

[18] "Nada que le pareciera formalmente sencillo, nada que estuviera formalmente resuelto podía interesarle" (Sarlo, "El mejor" 1). Para Sarlo, Saer es el autor de "las frases más complejas y musicales escritas en el castellano del Río de la Plata" (Sarlo, Escritos 304).

[19] El tema y las ideas de "La condición mortal" se completan, se amplifican y despliegan en "La política, la devastación” (Sarlo), una extensa y detallada exploración de las dimensiones ideológicas, políticas e historiográficas de la ficción de Glosa, en gran medida derivada y claramente gobernada por el asedio abierto en "La condición mortal". Sin duda, "La política, la devastación" es uno de los trabajos más notables de Sarlo, una especie de ejemplar — en el sentido kuhniano de la palabra - de crítica literaria e investigación textual y cultural.

[20] Ante la lectura sarliana de Glosa, conviene atender al hecho de que, para ponerlo en las palabras de Sontag, esa novela es "una historia poblada de personajes cuyas opciones y destinos son los de la presunta vida real corriente". Se dirá que en lo que tiene de anticipación de los destinos trágicos de los personajes enmadejados con la violencia política, no hay nada de "corriente" en esas vidas narradas. Pero es precisamente Tomatis quien en Lo imborrable bautiza los años del terrorismo de Estado, los años de las muertes, las desapariciones y los exilios de los personajes de Glosa, como "los tiempos que corren" (Saer). Igual que con Auschwitz, según Agamben, la excepción se ha vuelto la regla, el horror se ha vuelto lo común y lo corriente.

[21] En mi caso personal, recuerdo en cambio con nitidez la incomodidad persistente que me produjo el cambio de un Ángel Leto al otro, es decir, las incongruencias y diferencias - de Cicatrices a Glosa - en la historia de lo que parecía el mismo personaje, también retomado en "Amigos" - el cuento de La mayor de 1976-. Mi lectura en ese punto, aunque enfocaba no la prolijidad de un entramado, sino sus puntos mal tejidos, también era tributaria de un determinado estatus concedido a la firma autoral y de una consecuente expectativa de coherencia.

[22] No parece necesario extendernos aquí, pero el análisis del formalismo de Sarlo tal como lo describimos podría aplicarse a una lectura del comienzo del capítulo 6 de Zona Saer, en la que la filosofía saeriana de la percepción de lo material se describe en términos sartreanos y se explica (se lee), otra vez, como una impugnación del realismo a la luz de la teoría sobre las tensiones entre la narración y la descripción propuesta por G. Genette en Figures II (Sarlo, Zona Saer 101-106).

[23] Pienso especialmente en ese entre, esa atopía intersticial donde — según Agamben - el testigo, el poeta, el sujeto en todas sus variantes pasa por un instante de fuga de sí y es nadie.

[24] Parafraseo la fórmula con que Alberto Giordano — de un modo que no ha perdido nada de su agudeza crítica ni de su vigencia - se refería a la escritura de Saer en "El efecto de irreal" (1992). 
[25] Por supuesto, no pretendo sugerir que el tenor centralmente intelectivo de lo que Sarlo lee en Saer excluya cualquier intervención de dimensiones y efectos emocionales, lo que deseo subrayar es que en esa lectura se trata principalmente de interrogar e inferir el sentido. El horizonte teórico de esta perspectiva es complejo e involucra, de un modo selectivo, creativo y cambiante, una relación crítica con escritos que van de los formalistas rusos a Bajtín, de Jakobson a Barthes, de Theodor Adorno y Benjamin a Raymond Williams y Edward Said; mientras tienden a restringir, minimizar o suprimir el compromiso con otras matrices filosóficas (v. g. la que va de Blanchot a Nancy o el psicoanálisis, por mencionar apenas las más eminentes).

[26] El propio Saer describió, de un modo similar al beckettiano, su método como el de un poeta de la prosa narrativa, por ejemplo, cuando lo comparó con las sucesivas capas de pintura que ciertos artistas superponen sobre la superficie de la tela, ignorando a menudo cuántas capas serán, cuál será la última. Véase "Razones" (Saer), pero también la descripción del método de trabajo de la pintora Rita Fonseca en Glosa. Interesa destacar que lo que, según Saer, resulta de esa insistencia a tientas, conjetural y exploratoria del artista es una "aglomeración sensible", son "formaciones", una especie de materiación en la que, de la ejecución artística, ha salido de pronto algo en lo que es posible entrever el tenor de lo real.

[27] Uso disyunción con las orientaciones en las que se usa esta palabra en las traducciones de escritos sobre literatura de Paul de Man y de Jacques Rancière, especialmente.

\section{Licencia Creative Commons CC BY 4.0}

Cómo citar este artículo: Dalmaroni, Miguel. "La forma perfecta: Sarlo lee a Saer". Cuadernos de Literatura, vol. 24, 2020. https://doi.org/10.11144/Javeriana.cl24.fpsl 